\title{
A Few Proposals for Research-based Teaching Project in Chinese Universities- A Case Study of Dalian Nationalities University
}

\author{
Huiping TAN $^{1}$, Raye $\mathrm{Ng}^{2}$, Li CAI ${ }^{1, *}$ \\ ${ }^{1}$ International Business School, Dalian Nationalities University, Dalian, China \\ ${ }^{2}$ Business School, University of Cumbria, Lancaster, U.K \\ *Corresponding author: caili@dlnu.edu.cn
}

Received August 28, 2013; Revised September 08, 2013; Accepted September 21, 2013

\begin{abstract}
This paper describes the design of "Headline News Report on International Business" research-based teaching project of the national bilingual model course "International Business" at Dalian Nationalities University of China and then analyses the implementation and effects of this teaching project. Finally, this paper puts forward some suggestions and reflections of the improvement of the teaching project for bilingual business courses for universities of China.
\end{abstract}

Keywords: research-based teaching, Bilingual Course, Headline News Report, International Business, teaching project

Cite This Article: Huiping TAN, Raye Ng, and Li CAI, "A Few Proposals for Research-based Teaching Project in Chinese Universities- A Case Study of Dalian Nationalities University." American Journal of Educational Research 1, no. 8 (2013): 313-318. doi: 10.12691/education-1-8-8.

\section{Introduction}

Dalian Nationalities University of China introduced its first "International Business (Bilingual) Course" in 2004. In 2009, the course was praised as a national bilingual model course of China. In this course, "Headline News Report on International Business" teaching project functions as research-based teaching practice. This project enables students to comment on the ongoing international business events by composing academic papers and presenting speeches in accordance with the instruction and guidance of instructors of national bilingual model course "International Business". Since 2006, more than 800 students have participated in this project. Nearly 800 copies of questionnaires show that more than $90 \%$ of the students devoted themselves to this project. They believed that this project has made them learn to explore the field of international business through "this toilsome and challenging process", however they "feel joyful for the achievements after overcoming difficulties of finishing assignments” of this teaching project.

\section{Goals and Purposes of "Headline News} Report on International Business" Research-based Teaching Project

\subsection{Extending Teaching}

Content and
"International Business (Bilingual) Course" adopts authoritative, academic and original English textbooks and has updated the versions of textbooks three times since 2004. However, even the latest edition of textbook hinders students to learn about the latest academic information. Fortunately, the research-base teaching project "Headline News Report on International Business" tries to make up for this shortcoming.

"Headline News Report on International Business" teaching project is involved with what just happened as well as the ongoing domestic and international hot business topics, reflecting the status quo and the trends of the development of world economy. For example, students have analyzed the following topics: China as the Second largest Economy: Opportunities and Challenges; Boao Forum for Asia: Asia Searching for Win-Win; 2010 Tianjin Summer Davos: Focusing on Sustainable Growth Amid Recovery; Analysis of the Greek debt crisis; Drawing Lessons from the Toyota Recall Crisis; Geely Buys Volvo in Biggest Overseas Foray; On China’s first Case of Anti-dumping and Anti-subsidy; Both Sides Suffer: EU’s Anti-dumping On Chinese Bicycles.

All of these themes allow students to notice more and more current business events, broaden their vision, enrich the connotation of the course of international business and strengthen their professional knowledge.

\subsection{Carrying out Research-based Teaching Methodology and Cultivating Students' Awareness of Innovation}


Research-based teaching helps students study and practice under the guidance of instructors[1]. The purpose of research-based teaching is to develop students' awareness and spirit of innovation [2].

In the research-based teaching project, instructors create academic atmosphere for students which inspires them to explore the academic field independently and actively, absorb knowledge as well as solve problems [3]. As a result, students' creativity will be cultivated and their comprehensive abilities will be intensified.

In "Headline News Report on International Business" teaching project, students are required to explore independently in the international business field. They should collect information extensively, target their own interesting news, investigate the news background, analyze the news and make personal opinions. This project transforms teaching from a simple lecture-based "indoctrination" mode into an interactive mode that instructors and students conduct research together, and students find problems and solve problems under the guidance of instructors in practice. Regardless of all evaluation levels, for students, what they experience will be the valuable wealth in their academic lives.

\section{Design and Implementation of "Headline News Report on International Business" Research-based Teaching Project}

\subsection{Process of Implementation of This Project}

Instructors explain rules of the project to students and students are informed with tasks. Before the project, instructors describe the requirements in detail with demonstration, and provide templates for papers, multimedia courseware and presentation. Instructors distribute assessment form and questionnaires to students in order to let students understand the tasks, procedures and methods in all sectors, as well as make effective and reasonable arrangements.

When students are involved in the project, instructors should act as followers and guiders. After instructors determine the order in which students give presentation, the students will begin the independent research project. During this process, instructors inquire and urge students, and discuss with them about the problems and difficulties on topic selection, data collection, structure formulation and presentation preparation; then, instructors provide appropriate help and encourage students to finish this project. Usually, instructors need to invite the most outstanding students to join in the project and complete tasks as pioneers, and then make a detailed review on their papers, multimedia courseware and presentation, as well as point out their strengths and weaknesses for other students' reference in class.

Instructors comment on the performance of every student, and then students give feedback and suggestions to the instructors. After all students complete tasks, instructors will conduct one-on-one review on their papers, multimedia courseware and presentation in accordance with the assessment criteria. In addition, instructors should evaluate students' efforts.

Stringent requirements make students undertake a lot of pressure. In practice, the vast majority of students pay a great deal of efforts whether they are driven by pressure or interest as well. Therefore, instructors should recognize this and back up them, and let them discover their own potentials which will facilitate student's future growth.

After experiencing the whole process of the project, students can re-think about the meaning and effects of the project by filling out questionnaires. Additionally, they should make evaluation and recommendations for the project to improve and perfect the teaching project.

\subsection{Design of Student's Activity of This Project}

\subsubsection{Student's Activity: Academic Paper Composing}

The title should be formatted in an hourglass style; the first line longer than the second, the second line shorter than the third. Use numerical superscript callouts as shown in this template to link authors with their affiliations. Corresponding author should be denoted with an asterisk as shown. Email address is compulsory for the corresponding author.

Topic: Students can choose their own topics which are related with the domestic and international economy and trade in the current year. The instructors recommend that students need acquire diversified international business information through the Internet, libraries and other channels before selecting subjects; then, they should find the topics which they themselves or their teams are interested in; by way of brainstorming, they should define headings and subheadings to outline their own academic papers.

Frame Work: The title of paper should be concerned with the current international business and clarify the essence of student's papers. The abstract should contain main points of papers. Keywords should be appropriate. A paper should include "foreword" and 3 or 4 subheadings. The ending should conclude the paper, put forward suggestions and forecast the future. There are at least five references with Harvard System of Referencing Style in the paper. The strict framework structure can prevent students from downloading papers from the Internet directly or pieces of paragraphs on the Internet. The instructors also specifically emphasize academic honesty and examine students' papers through the online plagiarism checker.

Source: Data sources which the instructors provide for students include the online information of authoritative organizations (such as World Trade Organization, International Monetary Fund, the United Nations Conference on Trade and Development Report, Ministry of Commerce of China); the websites of authoritative newspapers and professional magazines; the academic journals and e-books. The instructors hope students to visit English websites to improve their English reading skills, and avoid students misunderstanding and grammatical errors incurred by translation.

Length and Format: Each paper of every student will be finished within 1,300 to 1,500 words. Templates of paper are offered. Pages, font and font size should be set in 
accordance with the typesetting requirements on academic papers.

Submission: Paper printed in A4 should be submitted on the stipulated date, while the paper in the electronic version should be sent to the Blackboard network learning system of Dalian Nationalities University. Late submission should be punished according to the delayed days.
Language and Weigh: The main body of paper is required to be finished in English; the topic and keywords are in English and Chinese; the abstract is written in Chinese. Academic paper writhing accounts for $10 \%$ of the total final score of the course of students.

Table 1. Assessment Form of Student's Academic Writing Activity of "Headline News Report on International Business” Teaching Project

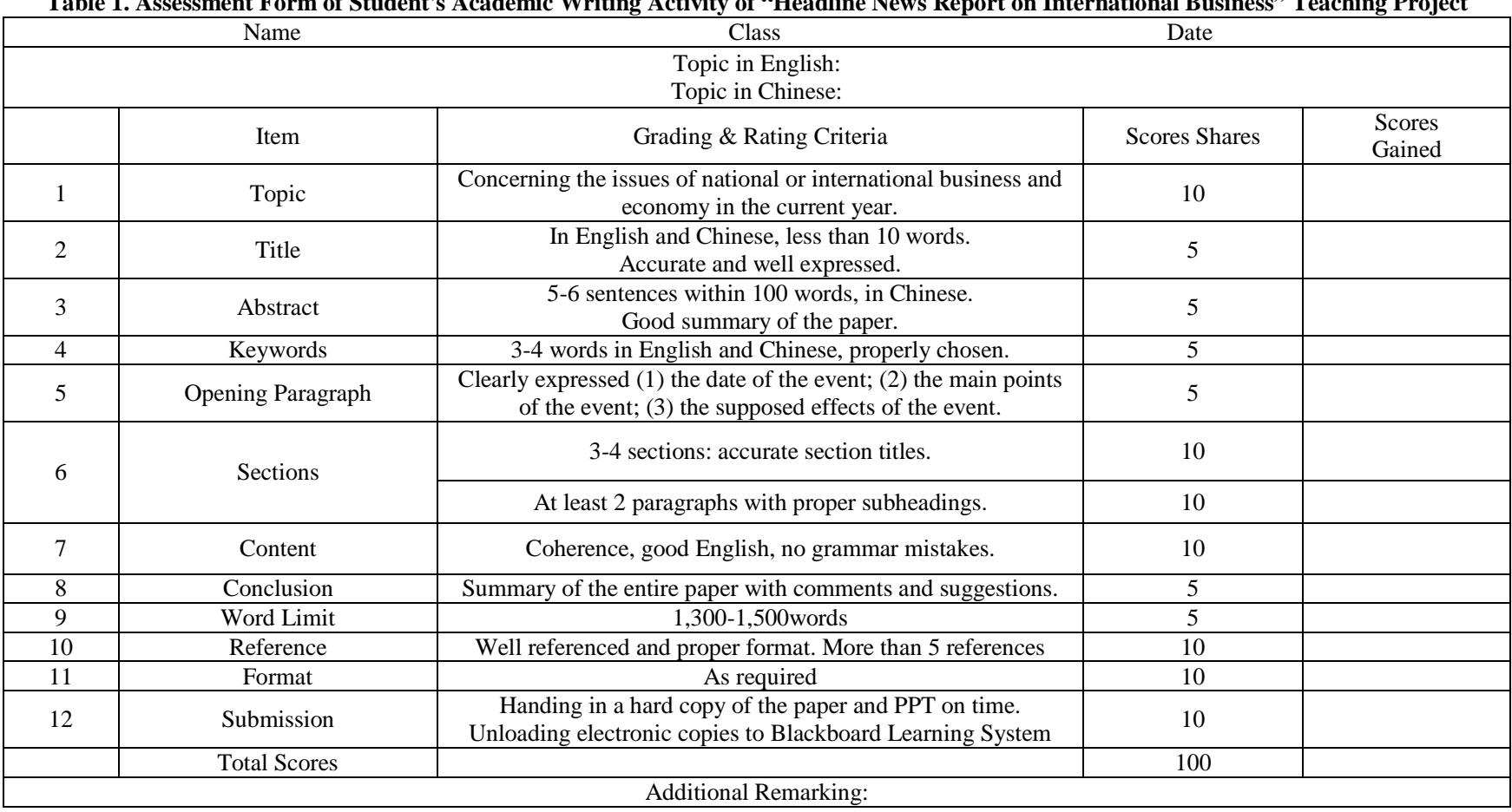

\subsubsection{Student's Activity: Multimedia Courseware}

PowerPoint slides: no more than 18 pages, between 200-300 words; long sentences are not allowed, while only points or short phrases are permitted.

Structure of PPT: the same structure with the academic paper, covering the main content.

Effect of PPT: definite, concise, illustrated and highlighted.

Submission: the paper printed in A4 should be submitted on the stipulated date, while the paper in the electronic version should be sent to the Blackboard network learning system.

\subsubsection{Student's Activity: Presentation}

English Level: accurate pronunciation, smooth and natural expression, and normal speech speed.

Manner: natural and proper postures, appropriate facial expressions, eye contact with the audience, vigorous and impressive emotion, clear and melodic voice, as well as appropriate dressing.

Time Limit: 4.5 to 5 minutes.

Weigh: presentation accounts for $10 \%$ of the total final score of the course of students.

Table 2. Assessment Form of Student's Presentation Activity of “Headline News Report on International Business” Teaching Project

\begin{tabular}{|c|c|c|c|c|}
\hline & Name: & Class: & Date: & \\
\hline & & $\begin{array}{l}\text { Topic in English: } \\
\text { Topic in Chinese: }\end{array}$ & & \\
\hline & Item & Grading \& Rating Criteria & $\begin{array}{l}\text { Scores } \\
\text { Shares }\end{array}$ & Scores Gained \\
\hline 1 & Design & Clear theme and good structure. & 10 & \\
\hline & & Fluent English, no reading the paper. & 10 & \\
\hline$?$ & Enolisb Droficionc & Normal speed: not too fast, not too slow & 10 & \\
\hline 2 & Engnisn Proniciency & Good voice, clarity and variety. & 5 & \\
\hline & & Good pronunciation. & 5 & \\
\hline & & $\begin{array}{c}\text { Natural and appropriate gestures with good facial } \\
\text { expression. }\end{array}$ & 5 & \\
\hline 3 & Manner & Enough eye contact with the audience. & 10 & \\
\hline & & Enthusiastic, high mood, attractive, impressive. & 15 & \\
\hline & & Proper or professional dress. & 5 & \\
\hline 4 & Time Limit & Within 4.5 to 5 minutes. & 10 & \\
\hline & & Well-designed PPT with visible text. & 5 & \\
\hline 5 & PPT & 200-300 words, using bullet points. & 5 & \\
\hline & & No more than 18 slides. & 5 & \\
\hline & Total Scores & & 100 & \\
\hline & & Additional Remarking: & & \\
\hline
\end{tabular}




\subsubsection{Student's Activity: Questionnaire}

Questionnaire for "Headline News Report on International Business" of International Business (Bilingual) Course not only reflects the feedback from students, but also plays a guiding role for students to participate in this project. Therefore, the instructors usually hand out the questionnaire to students at this beginning of the project. Each student will complete and hand in the questionnaire as soon as they finish their tasks. Students are required to answer the questions in the questionnaire and write down their true feelings, evaluation and recommendations.

Table 3. Questionnaire of Students for “Headline News Report on International Business” Teaching Project

\begin{tabular}{|c|c|c|c|c|c|}
\hline 1. Do Not Agree & 2. Not Sure & \multicolumn{4}{|c|}{ 4. Strongly Agree } \\
\hline 1. & I need to collect considerable materials to write a 1,500-word article. & 1 & 2 & 3 & 4 \\
\hline 2 & I have to analyze, screen and summarize information before determining a title. & 1 & 2 & 3 & 4 \\
\hline 3 & It is difficult to prepare all English titles. It is a challenge for me. & 1 & 2 & 3 & 4 \\
\hline 4 & I notice the relevance and logics between different parts of the report. & 1 & 2 & 3 & 4 \\
\hline 5 & I learn how to use Harvard System of Referencing and understand the academic integrity & 1 & 2 & 3 & 4 \\
\hline 6 & I have a deep understanding of the 1,500-word article, and I can design 200/300-word multimedia courseware. & 1 & 2 & 3 & 4 \\
\hline 7 & It takes me at least 40 hours from searching information to presentation. & 1 & 2 & 3 & 4 \\
\hline 8 & I can design better multimedia courseware than before. & 1 & 2 & 3 & 4 \\
\hline 9 & I learn about the text layout. & 1 & 2 & 3 & 4 \\
\hline 10 & I am able to use English commerce websites effectively. & & & & \\
\hline 11 & I find it is not difficult to read academic articles on English websites. & 1 & 2 & 3 & 4 \\
\hline 12 & I make practice to make my English speech fluent and impressive. & 1 & 2 & 3 & 4 \\
\hline 13 & Before my presentation, my mind is full of news and English words. & 1 & 2 & 3 & 4 \\
\hline 14 & During the presentation, I am in high spirits and have eye contact with the audience. & 1 & 2 & 3 & 4 \\
\hline 15 & In order to complete the presentation in 5 minutes, I must state main points with a perfect structure. & 1 & 2 & 3 & 4 \\
\hline 16 & I pay more attention to international business news now. & 1 & 2 & 3 & 4 \\
\hline 17 & I have sense of accomplishment when I finish my English article. & 1 & 2 & 3 & 4 \\
\hline 18 & This project creates huge pressure for me, however the achievements make me satisfied. & 1 & 2 & 3 & 4 \\
\hline 19 & If there is a chance, I will be able to do better. & 1 & 2 & 3 & 4 \\
\hline 20 & I feel tired to participate in this project, however I know it is harder for instructors to design this project. & 1 & 2 & 3 & 4 \\
\hline
\end{tabular}

\section{Effects and Evaluation of "Headline News Report on International Business" Research-based Teaching Project}

From 2006 to 2012, the instructors received nearly 800 copies of questionnaires from students. More than $90 \%$ of the students believed that this teaching project was useful and helpful for them in enhancing professional knowledge, improving English, intensifying learning ability and leveling up their comprehensive quality. More than $90 \%$ of the students expressed satisfaction on their own efforts. Over $95 \%$ of the students wished to have more opportunities to participate in the similar projects, and they thought that the process meant the growing experience of themselves.

\subsection{Collecting Information}

Students are advocated to collect and select professional information in English. Generally speaking, for a news report within 1,500 words, students have to collect the news materials beyond 15,000 words. Usually, they need to visit all websites related with the target news. If they want to analyze other news, they need do more work.

While seeking and collecting information, students are increasingly familiar with English websites, they learn to find what they need from considerable English information, select and summarize materials.

Each semester, the news report written by 120 students nearly covers all of the major international business events in the world in the current year, which not only increases the students' professional knowledge, but also cultivates their professional sensitivity.

\subsection{Formulating the Structure of Papers}

Students' analytical skills and logical thinking are cultivated. Students are required to classify filtered materials and set subheadings. Students should also take the correlation between parts of papers into account, and further analyze and summarize the content of each part.

\subsection{Choosing Titles}

Students' English abilities are developed. It is a challenge for students to set all titles which imply the meaning of papers accurately. They need to read materials repeatedly, understand information correctly and find appropriate vocabulary. Students said, "Sometimes, in order to elect a proper English title, we have to look over English materials several times." Reading and analysis effectively improve students' English proficiency.

\subsection{Making Multimedia Courseware}

Student's abilities in using computer are trained. According to the project requirements, students should only use 200-300 words to expound the main content of a 1,500-word paper by virtue of multimedia courseware with reasonable structure. Through multimedia courseware design, students enhance their English understanding and generalizing abilities.

\subsection{Preparing Presentation}

Students' spoken English is exercised. During the presentation, students are not permitted to take any 
materials except multimedia courseware which only contains 200-300 words. The presentation should be completed within less than 5 minutes. It is a challenge for most students to give speech in English. Many students said that they were always thinking about presentation, even speaking English in their dreams. This is not only an opportunity for students to speak English, but also a chance for them to break through the bottleneck in studying English.

\subsection{Feedback from Students}

For students, the self-confidence is built up, and the motivation of learning is stimulated through the this project. Students stated their thought in the questionnaire:

"We actually experienced from "have to" to "want to". Only we take part in the project, we can have gains after pains."

"I feel my experience in presentation is not enough, I did not reach my usual academic level. But, I am still happy. The process was 'tough', but I learned a lot.”

"At first, I was reluctant to participate in this project. Later, the success of my classmates changed my thought. I began to look forward to this presentation. Upon completion, I felt joyful, because I not only gained knowledge and information in the process, but also I found my confidence when I was standing on the podium. This presentation made me acquire many things."

"If not being 'forced' by teachers, I thought I would not say anything in front of the whole class on my own initiative. After the speech, I think the greatest enemy is myself."

“This project gave us many opportunities to 'do' something. It is a standardized, professional training for me.”

"Presentation gave each student an opportunity to show, especially for timid and nervous students just like me. Through the presentation, my speaking ability is improved. I hope to have another opportunity to improve myself, and I believe I will do better!”

"This is my first presentation in college, especially I finish it in English. Thank my teacher for giving me such a valuable opportunity. The result is important, but the process is more important. This opportunity enabled me to learn a lot, and it will be an unforgettable memory."

"In the process of completing the assignment, I really learned a lot. Although the process was very tangled, I achieved much. In this project, I found my shortcomings. In the future, I want to constantly improve myself in order to thank my teacher."

\section{Reflections and Suggestions of} "Headline News Report on International Business" Research-based Teaching
Project

\subsection{Designing the Teaching Project Flexibly}

As for rulemaking, the instructors absorb the advanced teaching philosophy and methods of western countries; stipulate scoring criteria after consulting the evaluation system and indicators of teaching projects of European and American universities; besides, the instructors also make some innovation on the basis of the successful experience of foreign counterparts [4].

Different rules of teaching projects reflect different anticipated teaching goals. The rules which are suitable for students and conductive to the realization of teaching objectives are the best rules. If students have a high academic level, instructors can set higher academic goals for the research-based project. The structure of a paper may contain Introduction, Literature Review, Methodology and Finding [5].

In the bilingual teaching, if instructors want to greatly improve students' English skills, they can extend the speech time and strengthen the "Question and Answer" after speeches of students. If instructors hope to cultivate students' team sprit, they can take the form of grouping. Instructors should sum up experience from the practice and continuously improve rules to enhance the operability and effectiveness of the instructional design [6].

\subsection{Comment on Students' Activities in Class Appropriately}

Instructors should not only spend plenty of time in design of this teaching project, but also have abundant expertise, excellent English and good knowledge of news and current events; otherwise, instructors will feel embarrassed in front of all students.

When instructors make comments, they should be sensitive to the psychological state of students, should not harm their self-esteem while pointing out their deficiencies. The instructors tend to encourage and inspire students. Some students think that their articles and speeches are not good enough, which implies that they are eager to succeed and they believe they can do better. The goal of the teaching does not lie in giving scores to students, but enabling them to discover their own potentials, stimulating their enthusiasm for learning and cultivating their self-confidence.

\subsection{Focus on the Different Performance of Students in Teaching Project}

The wonderful performance of outstanding students will affect the enthusiasm of ordinary students, and even arouse the pain and resentment of the latter. To encourage all students, instructors can divide students into groups and appoint a keynote speaker for each group to complete the key part in presentation, while other students make speeches by sortition. Through "Contribution Rate Table”, the students who make more contribution can be granted with more rewards; "more pay for more work" can make students feel fair and transparent.

\subsection{Arranging Teaching Project Reasonably According to Class Types}

In the class with numerous students, it is difficult to carry out "Question and Answer" which can reflect understanding and views of students truly. In this case, the grouping should be adopted, and the presentation time should be shortened, such as 10 minutes for five students. The topics can be diffused, thematic or confrontational style. Each student is responsible for his own part; all parts of the project should be related and complementary. 
For the smooth progress of the project, instructors should consider students' grades, professional knowledge and English proficiency. Usually, the research-based teaching project "Headline News Report on International Business" is carried out in the sixth semester, namely the second half of the third year at university. At this time, students have some expertise and are familiar with bilingual programs. If the project commences too early, the anticipated effects will not be realized easily. Instructors can guide students in lower grades to narrate news or events simply.

\section{Acknowledgement}

This research is supported by "Research on the Key Elements of International Business Open Courseware" Teaching Reform Project of Dalian Nationalities University (2013-6) and supported by "the National Model
Course for International Students Project" of Ministry of Education of China (2013-1113).

\section{References}

[1] Bie Dunrong, "Research on the Implementation Requirements of Research-based Teaching", China University Teaching, 264 (8). 10-12. 2012.

[2] Fan Quncheng, Xu Tong, Xi Shengqi, Wang Yuyue, "Practice of Research-based Teaching in the Fundamentals of Materials Science Course", China University Teaching, 264 (8). 61-62. 2012

[3] Xu Fengsheng, "The Theoretical Exploration on Research Teaching and its Practice", Higher Education of Sciences, 106 (6). 45-48. 2012.

[4] Zhang Anfu, "Reform of Teaching Methods and Explore Research Teaching", China University Teaching, 257 (1). 65-67. 2012.

[5] Tan Huiping, Research-Based Teaching Design for International Business, Dalian University of Technology Press, Dalian, 2011.

[6] Tan Huiping. Heanline News Report on International Business, , Dalian University of Technology Press, Dalian, 2011. 